\title{
Making the Conference Scene Virtual
}

Nathan S. Blow, Ph.D.

Editor-in-Chief, BioTechniques

Earlier this year, the editors and I discussed our interest in organizing a scientific symposium that would focus on the latest trends in methods development and their applications in various areas of biology. Despite our enthusiasm, the challenge during those early meetings was determining logistics: where to host the conference, for how many days, and who would speak. As we started to tackle the locale question, someone mentioned the idea of a virtual symposium: a free, one-day event featuring a dozen or more speakers working at the cutting-edge of genomics and proteomics research-all occurring entirely on the web. I liked the topics, but not having ever attended a virtual event before, I was skeptical.

In the ensuing weeks, we took a closer look at what a virtual symposium could offer our readers. It was important for us to create an event that would attract the greatest number of young scientists, who we know have limited travel resources. While there is no question that it's refreshing to get out of the lab and travel to a conference, the time and expense of such trips makes it necessary for most researchers to select only those that are precisely focused on their own research aims.

But in our line of work, we see methods and techniques cutting across disciplines all the time, making it even more essential to attract a diverse number of attendees. A free virtual event focusing on emerging methods-with access from any location around the globewould give us the opportunity to communicate to a larger audience that was no longer fettered by the details of getting to us. Indeed, a virtual event enhanced all of our goals. We would be able to deliver news and developments to scientists working directly at the bench without them ever having to leave their labs.

After recognizing the benefits of such a format for the BioTechniques community, the specifics quickly fell into place. Our first symposium, titled "The Genome and Beyond," will take place on 5 Oct., 2011. There will be 12 speakers presenting across four topic sessions during the day-long event-next-generation sequencing, epigenetics, proteomics, and cell analysis-all as part of an overall theme exploring genome structure and function and the implications for proteins and cells.

For those of you wondering how it will all look, the virtual event will appear very similar to a traditional conference hall. The event will comprise various online seminar rooms in which to attend live-broadcast presentations, as well as a poster hall, breakout meeting areas, and an exhibit floor with company displays. Attendees will be able to spend the day listening to relevant talks, engaging in question-and-answer sessions with speakers, perusing poster sessions, visiting exhibitors to learn about the latest products, and connecting with fellow visitors to network and form collaborations.

In the coming weeks, you'll be seeing additional information on the symposium, including a detailed list of presenters and abstracts, as well as a call for posters. At "The Genome and Beyond," the unique format and breadth of information will enable every one of our readers to find something of interest or usefulness to his or her career or lab routine, and foster collaborative engagement across all scientific disciplines. We could not be more excited for this event, and hope that you will be able to join us in October. The registration link can be found at www.BioTechniques.com/ symposium. [四

BioTechniques 50:203 (April 2011) doi 10.2144/000113642

To purchase reprints of this article, contact:

biotechniques@fosterprinting.com

\author{
A free virtual event \\ focusing on emerging \\ methods-with access \\ from any location around \\ the globe-would give \\ us the opportunity to \\ communicate to a larger \\ audience.
}

